Revista de

Contabilidade e

Organizações

www.rco.usp.br
DOI: http://dx.doi.org/10.11606/rco.v8i21.55603
Journal of

Accounting and

Organizations

\title{
O processo de convergência às IFRS e a capacidade do lucro e do fluxo de caixa em prever os fluxos de caixa futuro: evidências no mercado brasileiro
}

\author{
Márcio André Veras Machado ${ }^{\mathrm{a}}$, Augusto Cezar da Cunha Silva Filho ${ }^{\mathrm{b}}$, Aldo Leonardo Cunha Callados \\ ${ }^{a}$ Centro de Ciências Sociais Aplicadas, Universidade Federal da Paraiba \\ ${ }^{b}$ Universidade Federal Rural do Semi-Árido \\ ${ }^{a}$ Centro de Ciências Sociais Aplicadas, Universidade Federal da Paraiba
}

\section{Informações do Artigo}

Histórico do Artigo

Recebido: 02 Maio 2013

Aceito: 04 Outubro 2014

Palavras chave

Fluxo de Caixa

Accruals

Informação Contábil

\begin{abstract}
Resumo
Nos últimos anos, diversos estudos têm investigado a capacidade informativa do lucro contábil nos mercados de capitais. Uma parte dessas pesquisas está voltada em explicar a relação entre lucro, fluxo de caixa e accruals e os fluxos de caixa futuros. O foco é verificar qual informação contábil é mais relevante em prever o fluxo de caixa futuro. Nesse contexto, insere-se este artigo, que tem por objetivo analisar, em períodos 'pré', 'durante' e 'pós' processo de convergência às IFRS, a capacidade do lucro (líquido e operacional), fluxo de caixa e accruals em prever os fluxos de caixa futuros de 54 empresas não financeiras de capital aberto, durante os anos de 2006 a 2011. A metodologia utilizada, por meio de análise de regressão, baseia-se nos trabalhos de Greenberg, Johnson e Ramesh (1986) e Barth, Cram e Nelson (2001), onde se utilizou cinco variáveis contábeis para tentar explicar o comportamento do fluxo de caixa futuro. Os resultados revelam um aumento da capacidade explicativa do lucro líquido e do fluxo de caixa operacional combinado com os accruals, calculados pelo enfoque do fluxo de caixa, durante o período pós-convergência, comparativamente aos períodos pré e convergência parcial. Adicionalmente, os resultados evidenciam que os lucros desagregados em fluxo de caixa e accruals aumentam significativamente a capacidade preditiva dos fluxos de caixa futuros. Dessa forma, pode-se concluir que os accruals possuem um poder informativo adicional em predizer os fluxos de caixa futuros.
\end{abstract}

Copyright (C) 2014 FEA-RP/USP. Todos os direitos reservados

\section{INTRODUÇÃO}

As demonstrações financeiras das empresas brasileiras que passaram a ser publicadas a partir de janeiro de 2010 encerraram a primeira fase das mudanças na legislação que rege as práticas contábeis brasileiras, iniciadas legalmente pela Lei $11.638 / 07$, rumo à convergência às normas internacionais de contabilidade ou às International Financial Reporting Standards (IFRS). Dentre os benefícios da convergência das normas contábeis às IFRS, espera-se uma série de vantagens, tais como: maior transparência e comparabilidade dos demonstrativos financeiros, integração dos mercados financeiros, menores custos de financiamento, maior

Autor Correspondente: Tel + 5585 3216-7492

E-mail : mavmachado@hotmail.com (M. A. V. Machado); cezarfilho89@ hotmail.com (A. C. da C. Silva Filho); aldocallado@yahoo.com.br (A. L. C. Callado)

Universidade Federal da Paraíba, Centro de Ciências Sociais Aplicadas Campus I, Programa de Pós-Graduação em Administração - Cidade Universitária - Campus I - Castelo Branco - 58059-900 - Joao Pessoa, PB - Brasil credibilidade do mercado financeiro e, sobretudo, aumento na qualidade da informação contábil produzida (CALIXTO, 2010; NIYAMA, 2010).

Assim, torna-se oportuno investigar se as mudanças implementadas pelo processo de convergências às IFRS, regime contábil associado a uma maior qualidade e transparência das informações, proporcionaram maior relevância à informação contábil. Para Lopes e Martins (2007), a relevância da informação contábil reside em sua capacidade de prever fluxos de caixa futuros, pois se acredita que essas informações permitem o mercado fixar os preços das ações de uma empresa. Esse pensamento é compartilhado por Ross, Westerfield e Jaffe (2001), ao afirmarem que uma entidade é avaliada pela sua riqueza econômica expressa a valor presente, calculada a partir dos fluxos de caixa esperados no futuro e descontados por uma taxa de atratividade que reflete o custo de oportunidade das várias fontes de financiamento.

Nesse contexto, conhecer quais informações são relevantes em estimar o fluxo de caixa futuro é uma questão essencial para os participantes dos mercados de capitais. Dentre as informações contábeis relevantes, na predição dos fluxos de caixa futuros, estão o lucro e o fluxo de caixa (BARTH; CRAM; NELSON, 
2001; MALACRIDA, 2009). Para o FASB (1978), o lucro contábil é uma medida mais relevante que o fluxo de caixa, para prever os fluxos de caixa futuros. Corroborando o FASB, Lopes e Martins (2007) ressaltam que o regime de competência (utilizado no cálculo do lucro contábil) fundamenta-se justamente na ideia de relevância em prever os fluxos de caixa futuros. Contudo, ressalta-se que não há evidências empíricas definitivas que sustentem tais afirmações.

$\mathrm{Na}$ verdade, não há um consenso nos resultados das pesquisas empíricas relacionadas à capacidade do lucro e do fluxo de caixa na predição dos fluxos de caixa futuros. O trabalho de Greenberg, Johnson e Ramesh (1986) encontrou evidências de que os lucros são superiores aos fluxos de caixa passados, ao predizerem os fluxos de caixa futuros. Por outro lado, outros estudos, como os de Bowem, Burgstahler e Daley (1986) e Lustosa e Santos (2007), mostram que o fluxo de caixa é mais relevante do que o lucro, para prever fluxos de caixa futuros. Barth, Cram e Nelson (2001) e Malacrida (2009), utilizando mesma metodologia, encontraram evidências de que os accruals combinado com os fluxos de caixa operacionais possuem poder informacional adicional em prever os fluxos de caixa futuros. Os accruals são componentes que alteram o lucro ou prejuízo do período, mas que não influenciam imediatamente o caixa do período. Nesse sentido, não contempla os recebimentos e pagamentos associados às receitas e despesas antes reconhecidas (DECHOW, 1994; SLOAN, 1996; DECHOW; DICHEV, 2002).

Diante do exposto e tendo em vista as consequências que contemplam o conteúdo informacional das demonstrações contábeis quanto ao processo de migração das normas contábeis brasileiras aos padrões contábeis internacionais, surge a seguinte questão de pesquisa: qual o impacto da adoção das normas internacionais de contabilidade (IFRS) quanto à capacidade do lucro e de seus componentes (fluxo de caixa e accruals) em prever o fluxo de caixa futuro das ações negociadas na Bolsa de Valores de São Paulo (BM\&FBOVESPA)?

Dessa forma, este estudo tem por objetivo investigar qual variável é mais eficaz para explicar os Fluxos de Caixa Futuros, se é o Fluxo de Caixa das Operações (FCO), isolado ou em conjunto com os accruals ( $\triangle \mathrm{Acc})$, ou se é o Lucro Líquido (LL) ou Lucro Operacional (LO), em períodos 'pré', 'durante' e 'pós' processo de convergência às normas internacionais de contabilidade no Brasil.

Para tanto, apresenta-se uma comparação do $\mathrm{R}^{2}$ ajustado das regressões entre uma proxy de cada informação contábil (lucros líquido e operacional; fluxo de caixa operacional; e fluxo de caixa operacional combinado com os accruals) como variáveis independentes e o fluxo de caixa corrente como variável dependente, para o período de 2006 a 2011, de empresas brasileiras não financeiras de capital aberto.

Além desta, o presente artigo possui cinco partes. Na seguinte, apresenta-se o referencial teórico, onde serão abordadas a capacidade informativa da contabilidade e $o$ processo de Convergência às normas internacionais de contabilidade. Na terceira parte, abordar-se a metodologia. Na quarta, os resultados da pesquisa. $\mathrm{Na}$ quinta, a conclusão. E, por fim, as referências.

\section{REFERENCIAL TEÓRICO}

\subsection{Capacidade Informativa da Contabilidade}

O ponto inicial, quanto à discussão da capacidade informativa das demonstrações contábeis, é discutir seus objetivos, assim como suas características qualitativas (HENDRIKSEN; VAN BREDA, 2007). Segundo Edwards e Bell (1964), o principal objetivo a ser atingido pela reunião de dados contábeis é prover informação útil para a avaliação das decisões empresariais passadas e dos métodos utilizados nessas decisões. Corroborando com a essa afirmativa, Iudícibus (2010) salienta que o objetivo básico dos demonstrativos financeiros é fornecer informação útil aos seus usuários para a tomada de decisões econômicas.

Para o Financial Accounting Standards Board (FASB, 1978), o principal objetivo da contabilidade é "fornecer informações que sejam úteis para investidores e credores atuais e em potencial, bem como para outros usuários que visem à tomada racional de decisões de investimento, crédito e outras semelhantes" (FASB, 1978). Nesse mesmo sentido, o Internacional Accounting Standards Board (IASB), em seu pronunciamento IASB 1 , considera que o objetivo das demonstrações contábeis é fornecer informações sobre a posição econômicofinanceira e sobre o desempenho financeiro das entidades, que auxiliem um grande número de usuários em suas avaliações e tomadas de decisões econômicas.

Dessa forma, o objetivo da contabilidade está centrado na divulgação de informações úteis aos seus usuários. Contudo, por se tratar de informações a serem registradas, processadas e divulgadas pela contabilidade, existe a necessidade que se estabeleça algumas características dessas informações, de forma a torná-las efetivamente úteis. O Comitê de Pronunciamentos Contábeis (CPC 00, 2008) elenca um conjunto de tais características, entre as quais estão: a compreensibilidade, a confiabilidade, a comparabilidade e a relevância.

A informação é considerada relevante "quando influencia a decisão econômica dos usuários, ajudandoos a avaliar eventos passados, presentes ou futuros ou confirmando, ou corrigindo, suas avaliações passadas" (CPC, 2008, p. 32). Yamamoto e Salotti (2006) complementam, ressaltando que a informação contábil relevante é aquela que altera o estado da arte do conhecimento do seu usuário em relação à empresa, pois são essas informações que ele utiliza na solução de problemas.

Nesse sentido, ainda a respeito das informações contábeis teoricamente relevantes, Lopes e Martins (2007, p.65) expõem que:

investidores em mercado de capitais, por exemplo, estão preocupados com a capacidade da empresa em gerar fluxos de caixa no futuro, ou seja, na criação de valor e não somente com o fluxo de caixa gerado nos períodos passados. (...) Assim, a contabilidade é relevante à medida que fornece informações úteis a previsão dos fluxos de caixa futuros.

Corroborando Lopes e Martins (2007), Barth, Cram e Nelson (2001) expõem que as estimativas de fluxo de caixa são fundamentais para avaliar o valor da empresa como refletido no preço das ações, tornando o fluxo de caixa um constructo primitivo de avaliação. Nessa 
mesma linha, Ross, Westerfield e Jaffe (2001) afirmam que uma empresa é avaliada pela sua riqueza econômica expressa a valor presente, calculada a partir dos fluxos de caixa esperados no futuro e descontados por uma taxa de atratividade que reflete o custo de oportunidade das várias fontes de financiamento. Os autores ainda ressaltam que o valor de uma empresa depende de seu desempenho esperado no futuro, do que ela é capaz de produzir de valor (ROSS; WESTERFIELD; JAFFE, 2001).

Portanto, percebe-se que, para uma gama de usuários da informação contábil, principalmente em mercados de capitais, a relevância da informação contábil reside em sua capacidade de prever fluxos de caixa no futuro, ou seu valor intrínseco, pois sua avaliação é essencial na precificação de ativos e, consequentemente, na fixação dos preços das ações de uma empresa.

Assim, a questão gira em torno de saber qual informação deve ser utilizada por tais usuários, possibilitando estimar, da melhor forma, os fluxos de caixa futuros. Em outras palavras, qual variável tem maior poder preditivo dos fluxos de caixa futuros? No que se refere a esse questionamento, a literatura ressalta que, entre as informações contábeis relevantes na predição dos fluxos de caixa futuros, estão o lucro e o fluxo de caixa.

O lucro é uma informação contábil que se baseia no regime de competência, na qual se sustenta na junção de dois princípios: realização da receita e da confrontação das despesas. Quando observado esse regime, por exemplo, as receitas, despesas e custos devem ser registrados conforme sua ocorrência e não no momento da realização financeira. Além disso, seguindo o princípio da confrontação das despesas, as receitas devem ser reconhecidas de acordo com as suas despesas correspondentes para que se apure o resultado líquido do evento econômico em questão.

Dessa forma, o regime de competência está vinculado ao evento econômico ao invés do evento financeiro de entradas ou saídas de caixa, que seria representado pelo regime de caixa. Em decorrência disso, Malacrida (2009) ressalta que o lucro, que é apurado sob o regime de competência, apresenta diferenças em relação ao caixa gerado (fluxo de caixa), fazendo surgir o problema de diferenças intertemporais entre o reconhecimento econômico no resultado e seus reflexos no fluxo de caixa. A essas diferenças dar-se o nome de accruals. De acordo com Dechow e Dichev (2002), os accruals têm como função ajustar o reconhecimento dos fluxos de caixa no tempo, para que o lucro melhor mensure o desempenho da empresa, reduzindo os problemas de alocação intertemporal entre o regime de competência e o regime de caixa.

Ainda quanto à discussão, o FASB (1978) acredita que ao elaborar e apresentar as demonstrações financeiras, a evidenciação contábil deveria focar nos lucros, calculados pelo regime de competência, em detrimento ao fluxo de caixa, calculado pelo regime de caixa, pois se considera os lucros superiores ao fluxo de caixa em predizer os fluxos de caixa futuros.

Por outro lado, o IASB (2008) não enfatiza a figura do lucro quanto à sua capacidade preditiva dos fluxos de caixa futuros. Quando o IASB (2008) menciona que as demonstrações contábeis devem fornecer informações sobre a posição financeira, desempenho financeiro e sobre o fluxo de caixa da entidade, a fim de auxiliar os usuários na predição dos fluxos de caixa futuros, o documento fornece uma visão mais direcionada aos fluxos de caixa passados ao invés do lucro, em prever os fluxos de caixa futuros.

Com uma posição mais conservadora, o CPC (2008) destaca que tanto o lucro, quanto o fluxo de caixa, seriam úteis para os usuários estimarem os fluxos de caixa futuros da entidade. O Comitê expõe, em seu Pronunciamento Conceitual Básico (CPC 00), que "as informações sobre os resultados são úteis para prever a capacidade que a entidade tem de gerar fluxos de caixa a partir dos recursos atualmente controlados por ela" e complementa, afirmando que as informações referentes às mutações na posição financeira da entidade (Demonstração do Fluxo de Caixa, Demonstrações de Origens e Aplicações de Recursos e outras) também são úteis para fornecer ao usuário uma base para avaliar a capacidade da entidade de gerar caixa e equivalentes de caixa.

Hendriksen e Van Breda (2007, p.181) ressaltam que:

(...) a confiabilidade das predições que usam dados de fluxo de caixa é maior do que a de predições baseadas somente nos dados históricos de lucro. O contrário também verdadeiro. O lucro líquido convencional parece possuir conteúdo informacional além do contido nos fluxos de caixa. A divulgação de ambos os números, fluxos de caixa e lucro, portanto, é a situação mais desejável.

Para Lopes e Martins (2007), à luz da teoria da contabilidade, o lucro, calculado sob o regime de competência (accruals basis), é quem deve fornecer uma base mais adequada quanto à previsão dos fluxos de caixa futuros, ao invés do próprio fluxo de caixa corrente ou passado. Para esses autores, "a fundamentação do regime de competência está justamente na ideia de relevância, ou seja, na capacidade de previsão de fluxos de caixa" (LOPES; MARTINS, 2007, p. 68).

Ainda quanto à relevância do regime de competência, Martins (1990) ressalta que esse regime fundamenta-se nas realocações dos fluxos financeiros, por meio dos accruals, produzindo confrontações necessárias a uma boa análise da evolução da rentabilidade e da posição financeira das entidades, pois, pelo regime de caixa, a entidade poderá ter épocas com grandes desembolsos e época com grandes fluxos de entradas.

Quanto à importância de estudos que verifiquem o conteúdo informativo do lucro e o fluxo de caixa, Lopes e Martins (2007, p. 80) comentam que:

Os resultados desse tipo de investigação são extremamente importantes para a pesquisa e a própria prática em contabilidade, uma vez que é esperado que o accrual forneça informações adicionais ao fluxo de caixa. Espera-se que a presença de accruals (como métodos de depreciação e de reconhecimento de receitas e despesas) seja um mecanismo para que os administradores forneçam informações privadas sobre a empresa para o mercado. Assim, não é esperado que a evidenciação adicional do fluxo de caixa forneça informações mais relevantes do que as fornecidas pelo resultado. Como a presença de accruals é uma das características fundamentais do modelo contábil, a verificação de sua irrelevância coloca em dúvida a própria utilidade da contabilidade no contexto de mercado de capitais. 
Alguns estudos empíricos internacionais e nacionais foram realizados, com o objetivo de verificar o poder informativo do lucro e do fluxo de caixa, examinando qual a melhor informação na predição dos fluxos de caixa futuros. Dentre os trabalhos que analisaram essa questão, destacam-se: Bowen, Burgstahler e Daley (1986), Greenberg, Johnson e Ramesh (1986), Finger (1994), Barth, Cram e Nelson (2001) e Lev, Li e Sougiannis (2005).

Bowen, Burgstahler e Daley (1986), utilizando uma amostra de 324 empresas norte-americanas, no período de 1971-1981, avaliaram a capacidade do lucro e de cinco medidas de fluxos de caixa para prever, um e dois períodos à frente, os fluxos de caixa futuros. Os resultados indicaram que a medida tradicional do Fluxo de Caixa (isto é, lucro líquido mais depreciação e amortização) foi estatisticamente superior em predizer os fluxos de caixa futuros do que qualquer medida de lucro contábil, bem como em relação às outras medidas de cálculo do fluxo de caixa. Utilizando a mesma metodologia de Bowen, Burgstahler e Daley (1986), Arnold et al (1991) e Percy e Stokes (1992), investigando os mercados do Reino Unido e Austrália, respectivamente, concluíram que os resultados fornecem evidências consistentes com os achados de Bowen, Burgstahler e Daley (1986).

O estudo de Greenberg, Johnson e Ramesh (1986), usando dados de empresas norte-americanas, no período de 1963-1982, investigou a capacidade dos lucros e fluxos de caixas correntes em predizer os fluxos de caixa futuros. Os autores, para cada empresa da amostra, utilizaram dois modelos de regressão. O primeiro modelo utilizou os lucros passados para explicar os fluxos de caixa correntes (modelo do lucro) e o segundo utilizou dados de fluxos de caixa passados (com defasagens entre 1 a 5 anos) para explicar os fluxos de caixa correntes (modelo do fluxo de caixa). Assim, comparando os coeficientes de determinação de cada modelo, de cada empresa, verificava-se qual modelo tinha maior poder de previsão. Os autores concluíram que os lucros superavam os fluxos de caixa na previsão dos fluxos de caixas futuros.

Com outro enfoque, Finger (1994) testou a capacidade do lucro em prever lucros futuros e fluxos de caixa futuros para um a oito anos à frente, utilizando dados anuais de 50 empresas, no período entre 1935-1975. Como resultados principais, tem-se: no curto prazo, o fluxo de caixa tem melhor poder de previsão dos fluxos de caixa futuros do que os lucros. Contudo, no longo prazo, as duas medidas são aproximadamente equivalentes. Além disso, o estudo forneceu evidências de que o lucro ajuda a prever os lucros e fluxos de caixa futuros, mas não afirma que os lucros são melhores que os fluxos de caixa na previsão dos fluxos de caixa futuros.

Com uma análise complementar, Barth, Cram e Nelson (2001) desenvolveram um modelo, onde desagregam o lucro contábil em seus componentes: accruals e fluxo de caixa. O principal objetivo era fornecer evidências a respeito das relações existentes entre accruals, lucro, fluxo de caixa operacional e fluxo de caixa futuro, com foco no papel dos accruals na predição de fluxos de caixa futuros. Os resultados mostram que os lucros desagregados em fluxo de caixa e accruals agregados aumentam significativamente a capacidade preditiva para fluxos de caixa futuros. Dessa forma, os autores concluíram que os accruals possuem um poder informativo adicional em predizer os fluxos de caixa futuros.

Mais recentemente, em contraste aos achados de
Barth, Cram e Nelson (2001), Lev, Li e Sougiannis (2005), examinando a contribuição dos accruals na qualidade das informações financeiras, principalmente na previsão dos fluxos de caixa e lucros das empresas, concluíram que os accruals não melhoram à previsão dos fluxos de caixa, melhorando apenas marginalmente à previsão dos lucros. Adicionalmente, os autores ressaltam que o fluxo de caixa corrente, sozinho, supera o lucro contábil e o fluxo de caixa combinado aos accruals na previsão de fluxos de caixa futuros.

Ressalta-se que outros trabalhos (SLOAN, 1996; BARTH et al, 1999; BARTOV; GOLDBERG; KIM, 2001) também buscaram verificar a capacidade preditiva do lucro e do fluxo de caixa, porém relacionando tais variáveis com o preço e o retorno das ações como proxy para fluxos de caixa futuros esperados.

No Brasil, a discussão sobre a capacidade do lucro e fluxo de caixa em prever fluxos de caixa futuros é incipiente. Os trabalhos que tratam diretamente sobre o assunto foram desenvolvidos por Lustosa e Santos (2007) e Malacrida (2009). O trabalho de Lustosa e Santos (2007), utilizando metodologia semelhante ao trabalho de Lev, Li e Sougiannis (2005), evidenciou que a combinação dos accruals com o fluxo de caixa operacional não melhora as previsões que são feitas apenas com o fluxo de caixa operacional, revelando que o fluxo de caixa operacional é mais eficaz em prever os fluxos de caixa futuros do que o lucro desagregado em accruals e fluxo de caixa.

Em sentido contrário ao de Lustosa e Santos (2007), Malacrida (2009) encontrou evidências empíricas de que os accruals são relevantes para predizer o fluxo de caixa futuro e adicionam capacidade preditiva ao lucro corrente. A autora ressalta que o lucro corrente desagregado em fluxo de caixa operacional e seis componentes de accruals mostra-se mais relevante do que o lucro corrente na estimação do fluxo de caixa futuro.

Diante disso, as evidências empíricas relativas às previsões de fluxos de caixa futuros, utilizando os lucros e os fluxos de caixa como medidas de previsões, fornecem resultados contraditórios. Portanto, espera-se que este estudo contribua com esse campo de pesquisa em contabilidade.

\subsection{Processo de Convergência às Normas Internacionais de Contabilidade}

Considerando que o objetivo deste trabalho consiste em mensurar e analisar se houve aumento na capacidade do lucro e do fluxo de caixa em prever os fluxos de caixa futuros, no contexto da adoção das normas internacionais de contabilidade no Brasil, torna-se pertinente discutir alguns aspectos sobre a convergência das normas contábeis brasileiras às IFRS.

De forma geral, no Brasil, a adoção das IFRS compreendeu duas etapas. A primeira, desenvolvida em 2008, através da Lei 11.638/07 e aprovação de 15 Pronunciamentos Técnicos, a ser aplicada durante os anos de 2008 e 2009. A segunda, desenvolvida no decorrer de 2009, com a aprovação de outros 29 Pronunciamentos Técnicos, já com todos os procedimentos convergentes às normas internacionais e aplicados obrigatoriamente a partir de 2010. Assim, no Brasil, a adoção dos padrões internacionais foi exigida para os demonstrativos 
consolidados divulgados a partir de 2010.

O principal motivo para adoção das normas internacionais de contabilidade (IFRS) consiste na expectativa de aumento do nível de confiança das informações divulgadas, permitindo a aplicação de recursos com base em informações mais precisas. Além disso, espera-se que as novas práticas contábeis provenientes do processo de convergência proporcionem mais transparência e qualidade às informações contábeis apresentadas pelas entidades, principalmente as brasileiras, que são marcadas pela regulamentação de organismos governamentais (CALIXTO, 2010; LIMA, 2010; NIYAMA, 2010).

Nesse sentido, alguns trabalhos buscaram investigar os impactos das mudanças advindas da harmonização contábil às normas internacionais (IFRS). $\mathrm{Na}$ verdade, não há um consenso definitivo quanto a tais efeitos, alguns trabalhos mostram não haver impacto significativo e outros apontam melhorias na qualidade da informação contábil.

Em um dos trabalhos mais completos no que se refere ao assunto, Barth, Landsman e Lang (2008) investigaram empresas de 21 países, entre os anos de 1994-2003, e obtiveram evidências de que as normas internacionais aumentaram a relevância das informações contábeis, quando comparado aos padrões locais.

No mercado alemão, o trabalho de Hung e Subramanyam (2007), investigando uma amostra de empresas durante 1998-2002, fornecem evidências de que a variação do lucro e do patrimônio líquido apresentamse mais relevantes no modelo IAS em relação ao GAAP Alemão.

Por outro lado, o trabalho de Morais e Curto (2007), investigando empresas de Portugal, aponta que os lucros apresentaram uma redução de relevância com a adoção das normas internacionais de contabilidade (IFRS). Nesse mesmo sentido, a pesquisa de Niskanen Kinnunen e Kasanen (1998) revelou que as normas internacionais não proporcionaram incremento informativo às informações contábeis das empresas da Finlândia.

\section{PROCEDIMENTOS METODOLÓGICOS}

\subsection{Tipo e Método de Pesquisa}

Para responder ao problema de pesquisa, utilizarse-á da abordagem empírico-analítica. Segundo Martins (2002, p.34), “[...] são abordagens que apresentam em comum a utilização de técnicas de coleta, tratamento e análise de dados marcadamente quantitativos [...]. Têm forte preocupação com a relação causal entre variáveis. A validação da prova científica é buscada através de testes dos instrumentos, graus de significância e sistematização das definições operacionais".

\subsection{Amostra}

O processo de amostragem é não probabilístico, pois parte-se de um universo naturalmente restrito, já que a amostra foi escolhida a partir das empresas listadas na BM\&FBOVESPA, que são acompanhados pela Economática.
Para fazer parte da amostra, as empresas precisavam ter as seguintes características:

- $\quad$ ser uma empresa não financeira;

- ter informações disponíveis na base de dados da Economática, no período de 2006 a 2011;

- ter voluntariamente divulgado a DFC em todo o período.

As empresas financeiras (setor "finanças" e "fundos") foram excluídas das análises, como é comum em estudos dessa natureza (GREENBERG; JOHNSON; RAMESH, 1986; BARTH; CRAM; NELSON, 2001). Um das justificativas para exclusão dessas empresas é o fato de que elas são regulamentadas por órgãos com legislação específica, o que impacta na contabilidade, principalmente nos lucros e fluxos de caixas reportados (LAFOND, 2005).

Assim, após coletar os dados anuais das cinco variáveis necessárias, no período de 2006 a 2011, no banco de dados da Economática, a amostra final ficou composta por 54 empresas de capital aberto e não financeiras.

\subsection{Definição das Variáveis}

A medida de Fluxo de Caixa Operacional utilizada neste trabalho foi fornecida pelas empresas de forma voluntária, uma vez que sua obrigatoriedade deuse apenas a partir de 2008. O LL é a última linha da demonstração do resultado. Quanto ao LO, utilizou-se o conceito clássico, o EBIT (Earnings Before Interest and Tax). Os accruals foram calculados pelo enfoque do Balanço Patrimonial (BP), conforme Equação (1), e pelo enfoque da Demonstração do Fluxo de Caixa (DFC), conforme Equação (2).

Ressalta-se que a especificação dos accruals totais pelo enfoque do Balanço Patrimonial é bem estabelecida na literatura acadêmica (SLOAN, 1996; DECHOW; SLOAN; SWEENEY, 1995; MARTINEZ, 2001). Ela corresponde a uma estimativa aproximada da definição de accruals usada pelo FASB (RICHARDSON, et al., 2005), além de ser equivalente ao valor obtido pela diferença dada pelos accruals correntes e não correntes (MARTINEZ, 2001)

A razão da análise do cálculo dos accruals pelos dois enfoques justifica-se, pois, para Collins e Hribar (2000), a mensuração dos accruals pelo método do BP é susceptível a erros em sua estimativa, principalmente em situações de fusões, aquisições e operações descontinuadas.

Assim, a pesquisa também buscará verificar se, quando utilizado os accruals pelo enfoque da DFC, há uma melhor relevância na explicação dos fluxos de caixa futuros em comparação ao enfoque do BP.

$$
A c c B P_{t}=\left(\Delta A C_{t}-\Delta D_{i s p}-\Delta P C_{t}-\Delta D i v_{t}-\Delta I m p_{t}-D e p r_{t}\right),(1)
$$

Em que:

AccBP - Accruals totais da empresa calculados pelo enfoque do Balanço Patrimonial no período $t$;

$\triangle A C_{t-}$ variação do ativo corrente (circulante) da empresa 
no final do período $t-1$ para o final do período $t$

$\Delta P C_{t}$ - variação do passivo corrente (circulante) da empresa no final do período $t-1$ para o final do período $t$;

$\Delta$ Disp - variação das disponibilidades da empresa no final do período $t-1$ para o final do período $t$;

$\Delta D i v_{t}$ - variação dos financiamentos e empréstimos de curto prazo da empresa no final do período $t-1$ para o final do período $t$;

$\Delta I m p_{t}$ - variação dos impostos a pagar da empresa no final do período $\mathrm{t}-1$ para o final do período $\mathrm{t}$;

Depr- montante das despesas com depreciação da empresa durante o período $t$.

$$
A c c F C_{t}=\text { Lucrot }_{-}-\mathrm{Fl} \text { Caixa }_{t}
$$

Em que:

AccFC - Accruals totais da empresa calculados pelo enfoque do Fluxo de Caixa no período $t$;

Lucro $_{t}$ - Lucro Operacional (EBIT) no período $t$;

Fl_Caixa - Fluxo de Caixa Operacional da empresa no período $t$.

\subsection{Modelo Econométrico}

Para alcançar o objetivo deste trabalho, que é avaliar se adoção das normas internacionais de contabilidade no Brasil aumentou a capacidade do lucro e seus componentes (accruals e do fluxo de caixa operacional) em explicar os fluxos de caixa operacionais futuros das companhias abertas brasileiras, adaptou-se a metodologia dos trabalhos de Greenberg, Johnson e Ramesh (1986) e Barth, Cram e Nelson (2001).

Para tanto, utilizaram-se cinco modelos, onde se buscou verificar qual variável contábil melhor explica os fluxos de caixa futuros das empresas em análise. Além disso, buscou-se analisar se houve uma melhora na explicação de tais fluxos de caixa futuros durante os períodos 'pré', 'durante' e 'pós' processo de convergência às IFRS, uma vez que se espera que a adoção dos padrões contábeis internacionais (IFRS) assegure um conteúdo informacional superior em comparação aos padrões locais. Dessa maneira, foram estimadas cinco regressões, conforme equações 3 a 7 , para cada um dos três períodos analisados ('pré', 'durante' e 'após' processo de convergência às IFRS):

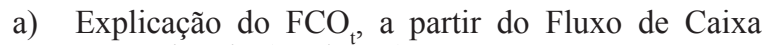
Operacional $_{\mathrm{t}-1}$ (modelo 1):

$$
\mathrm{FCO}_{\mathrm{it}}=\alpha+\beta \mathrm{FCO}_{\mathrm{i}, \mathrm{t}-1}+\varepsilon_{\mathrm{i}}
$$

b) Explicação do FCOt a partir do Lucro Líquidot-1 (modelo 2):

$$
\mathrm{FCO}_{\mathrm{it}}=\alpha+\beta \mathrm{LL}_{\mathrm{i}, \mathrm{t}-1}+\varepsilon_{\mathrm{i}}(4)
$$

c) Explicação do FCOt a partir do Lucro Operacionalt-1 (modelo 3):

$$
\mathrm{FCO}_{\mathrm{it}}=\alpha+\beta \mathrm{LO}_{\mathrm{i}, \mathrm{t}-1}+\varepsilon_{\mathrm{i}}(5)
$$

d) Explicação do FCOt a partir do desmembramento do Lucro Líquido em Fluxo de Caixa

Operacionalt-1 e Accruals pelo Enfoque do Balanço Patrimonialt-1 (modelo 4):

$$
\mathrm{FCO}_{\mathrm{it}}=\alpha+\beta \mathrm{FCO}_{\mathrm{i}, \mathrm{t}-1}+\mathrm{b} 2 \mathrm{AccBP}_{\mathrm{i}, \mathrm{t}-1}+\varepsilon_{\mathrm{i}} \text { (6) }
$$

e) Explicação do FCOt a partir do desmembramento do Lucro Líquido em Fluxo de Caixa Operacionalt-1 e Accruals pelo enfoque do Fluxo de Caixat-1 (modelo 5):

$$
\mathrm{FCO}_{\mathrm{it}}=\alpha+\beta \mathrm{FCO}_{\mathrm{i}, \mathrm{t}-\mathrm{1}}+\mathrm{b} 2 \mathrm{AccFC}_{\mathrm{i},-\mathrm{-}-\mathrm{i}}+\varepsilon_{\mathrm{i}}(7)
$$

Onde:

$L L_{i, t-1}=$ lucro líquido da empresa $i$ no período $t-1$;

$L O_{i, t-1}=$ lucro operacional da empresa $i$ no período $t-1$;

$F C O_{i, t-1}=$ fluxo de caixa operacional para a empresa $i$ no período $t-1$;

AccBP $_{i, t-I}$ Accruals pelo Enfoque do Balanço Patrimonial da empresa $i$ no período $t-1$;

AccFC $_{i, t-1=}$ Accruals pelo Enfoque do Fluxo de Caixa da empresa $i$ no período $t-1$.

Para analisar se houve um aumento ou diminuição na explicação dos Fluxos de Caixa Futuros, comparou-se o $\mathrm{R}^{2}$ Ajustado das regressões. Assim, se o $\mathrm{R}^{2}$ do período 'Pós Convergência' for maior que o $\mathrm{R}^{2}$ Ajustado do período 'Pré Convergência' ou 'Convergência Parcial', conclui-se que houve ganho informacional, em virtude das mudanças oriundas do processo de convergência às IFRS.

\section{APRESENTAÇÃO E ANÁLISE DOS RESULTADOS}

\subsection{Período "Pré Convergência" ou "BRGAAP":}

A análise da Tabela 1 evidencia a melhor proxy na explicação dos Fluxos de Caixa Futuros durante o período 'Pré Convergência', onde utilizou-se os anos de 2006 e 2007 na sua representação.

De acordo com a Tabela 1, todas as regressões estimadas mostraram-se significativas, em termos estatísticos, ao nível de $1 \%$, uma vez que os p-value obtidos pela estatística $F$ foram inferiores a 0,01 . Quanto à significância das variáveis, os resultados indicam que todas as variáveis, com exceção da variável $\mathrm{AccBP}_{t-1}$, mostraram-se significativas estatisticamente ao nível de $1 \%$.

O modelo 5 apresentou o maior poder explicativo do Fluxo de Caixa Futuro, com um Coeficiente de Determinação Ajustado ( $\mathrm{R}^{2}$ Ajustado) de 0,859, evidenciando que $85,9 \%$ da variação do Fluxo de Caixa Futuro $\left(\mathrm{FCO}_{\mathrm{t}}\right)$ é explicada pelas variáveis Fluxo de Caixa Operacional $\left(\mathrm{FCO}_{t-1}\right)$ combinado com os accruals, calculados pelo enfoque do Fluxo de Caixa $\left(\operatorname{AccFC}_{t-1}\right)$.

Esse resultado aponta que os accruals possuem um poder informativo adicional, uma vez que, ao desmembrar o Lucro Líquido (Modelo 2) em Fluxo de Caixa e accruals (Modelo 5), há uma melhor explicação dos Fluxos de Caixas Futuros. As evidências sobre o conteúdo informacional dos accruals corroboram com as pesquisas de Barth, Cram e Nelson (2001) e Malacrida 
(2009). Observa-se, ainda, que o Lucro Operacional (Modelo 3) é a segunda medida mais explicativa dos Fluxos de Caixa Futuros, apresentando um Coeficiente de Determinação Ajustado de 0,8510 .

Em seguida, o Fluxo de Caixa Operacional combinado com os accruals calculados pelo enfoque do
Balanço Patrimonial (Modelo 4) mostrou-se o terceiro mais explicativo, com um $\mathrm{R}^{2}$ Ajustado de 0,7731. Por fim, os Modelos 1 e 2 apresentaram um $\mathrm{R}^{2}$ Ajustado de 0,7729 e 0,7017 , respectivamente.

Tabela 1. Resultados das Regressões para o período 'Antes Convergência' ou BRGAAP

\begin{tabular}{|c|c|c|c|c|c|c|c|c|}
\hline \multicolumn{9}{|c|}{ Modelo 1* } \\
\hline Variáveis & Coeficientes & Erro Padrão** & Estatística $t$ & $p$-Valor & Estatística F & $p$-Valor & $\mathrm{R}^{2}$ & $\mathrm{R}^{2}$ Ajustado. \\
\hline $\mathrm{FCO}_{\mathrm{t}-1}$ & 0,906833 & 0,189421 & 4,787387 & 0,0000 & 365,2636 & 0,0000 & 0,7750 & 0,7729 \\
\hline \multicolumn{9}{|c|}{ Modelo 2* } \\
\hline Variáveis & Coeficientes & Erro Padrão** & Estatística $t$ & $p$-Valor & Estat. $\mathrm{F}$ & $p$-Valor & $\mathrm{R}^{2}$ & $\mathrm{R}^{2}$ Ajustado \\
\hline $\mathrm{LL}_{\mathrm{t}-1}$ & 1,649568 & 0,105085 & 15,69752 & 0,0000 & 252,8168 & 0,0000 & 0,7045 & 0,7017 \\
\hline \multicolumn{9}{|c|}{ Modelo 3* } \\
\hline Variáveis & Coeficientes & Erro Padrão** & Estatística $t$ & $p$-Valor & Estatística F & $p$-Valor & $\mathrm{R}^{2}$ & $\mathrm{R}^{2}$ Ajustado \\
\hline $\mathrm{LO}_{t-1}$ & 1,086551 & 0,071797 & 15,13367 & 0,0000 & 664,2406 & 0,0000 & 0,8523 & 0,8510 \\
\hline \multicolumn{9}{|c|}{ Modelo 4* } \\
\hline Variáveis & Coeficientes & Erro Padrão** & Estatística t & p-Valor & Estatística F & p-Valor & $\mathrm{R}^{2}$ & $\mathrm{R}^{2}$ Ajustado \\
\hline $\mathrm{FCO}_{\mathrm{t}-1}$ & 0,810935 & 0,149048 & 5,440781 & 0,0000 & 183,2937 & 0,0000 & 0,7773 & 0,7731 \\
\hline $\mathrm{ACCBP}_{\mathrm{t}-1}$ & $-0,223220$ & 0,550030 & $-0,405833$ & 0,6857 & & & & \\
\hline \multicolumn{9}{|c|}{ Modelo 5* } \\
\hline Variáveis & Coeficientes & Erro Padrão** & Estatística $t$ & $p$-Valor & Estatística F & $p$-Valor & $\mathrm{R}^{2}$ & $\mathrm{R}^{2}$ Ajustado \\
\hline $\mathrm{FCO}_{t}$ & 1,084008 & 0,059135 & 18,33107 & 0,0000 & 329,3389 & 0,0000 & 0,8625 & 0,8598 \\
\hline $\mathrm{ACCFC}_{\mathrm{t}-1}$ & 1,048846 & 0,349734 & 2,998981 & 0,0034 & & & & \\
\hline
\end{tabular}

*Todas as regressões estimadas (Modelo 1 ao Modelo 5) rejeitam a hipótese nula de normalidade dos resíduos. No entanto, considerando o Teorema do Limite Central e considerando o número de observações, o pressuposto da normalidade pode ser relaxado (BROOKS, 2002).

** Erros-padrão estimados, aplicando-se a matriz robusta de Newey-West. Esse método corrige o desvio-padrão, reduzindo os efeitos da autocorrelação serial e heterocedascidade.

Para detectar a presença de multicolinearidade, fez-se uso dos testes FIV (Variance Inflatiom Factor). Obteve-se um FIV de 1,5195 para as variáveis $\mathrm{FCO}_{\mathrm{t}-\mathrm{e}}$ e $\mathrm{ACCBP}{ }_{\mathrm{t}-1}$ e um FIV de 1,037 para as variáveis $\mathrm{FCO}{ }_{\mathrm{t}-1}$ e $\mathrm{ACCFC}_{\mathrm{t}-1}$, respectivamente, concluindo-se pela inexistência de colinearidade (LEVINE; BERENSON; STEPHAN, 2000).

\subsection{Período "Convergência Parcial ou Híbrido" ou "BRGAAP/IFRS"}

A Tabela 2 evidencia a melhor proxy na explicação dos Fluxos de Caixa Futuros durante o período da 'Convergência Parcial', que teve como marco inicial a promulgação da Lei ${ }^{\circ} 11.638 / 07$. Assim, utilizou-se os anos de 2008 e 2009 na sua representação. Ressalta-se que esse período é considerado a primeira fase do processo de convergência das normas brasileiras às internacionais.

De acordo com a Tabela 2, todas as regressões estimadas mostraram-se significativas em termos estatísticos ao nível de $1 \%$, uma vez que os p-value obtidos pela estatística $F$ foram inferiores a 0,01 . Em relação à significância das variáveis utilizadas, a estatística $t$ indica que todas as variáveis mostraram-se significativas estatisticamente ao nível de $1 \%$, exceto a Lucro Operacional (Modelo 3), que foi significativa ao nível de 5\%.

A regressão com maior poder explicativo foi o Modelo 4, com um Coeficiente de Determinação Ajustado de 0,9143, evidenciando que $91,43 \%$ da variação do Fluxo de Caixa Futuro( FCO, é explicada pela variável Fluxo de Caixa $\left(\mathrm{FCO}_{\mathrm{t}-1}\right)$ em conjunto com a variável accruals calculados pelo enfoque do Balanço Patrimonial ( $\left.\mathrm{ACCBP}_{\mathrm{t}-1}\right)$. Esse resultado, apesar de ser o modelo 4 o mais relevante, está alinhado ao resultado do período analisado anteriormente, visto que, novamente, os accruals possuem poder informativo adicional, quando analisado em conjunto com o Fluxo de Caixa Operacional $\left(\mathrm{FCO}_{\mathrm{t}-1}\right)$. Outro ponto a ser destacado é que esse período (Convergência Parcial) apresentou uma melhor explicação dos Fluxos de Caixa Futuros em comparação ao período anterior (Pré Convergência), uma vez que o $\mathrm{R}^{2}$ Ajustado passou de 0,8598 para 0,9143 .

Observa-se, ainda, que o modelo 5, que tem como variáveis independentes o Fluxo de Caixa Operacional $\left(\mathrm{FCO}_{\mathrm{t}-1}\right)$ e os accruals calculados pelo enfoque do Fluxo de Caixa (AccFC ${ }_{t-1}$ ), mostrou-se o segundo mais explicativo, com um $\mathrm{R}^{2}$ Ajustado de 0,9056. Esse resultado mostra, mais uma vez, o conteúdo informacional adicional dos accruals quando combinado com o Fluxo de Caixa Operacional. Como visto, nesse período (Convergência Parcial), os dois modelos mais explicativos foram justamente aqueles que tinham os accruals como variáveis independentes.

O modelo 1, que tem como variável independente o Fluxo de Caixa Operacional $\left(\mathrm{FCO}_{\mathrm{t}-1}\right)$, mostrou-se o terceiro mais explicativo, apresentando um $\mathrm{R}^{2}$ Ajustado de $88,03 \%$. Por fim, os Modelos 2 e 3, apresentaram $\mathrm{R}^{2}$ Ajustado de 0,8082 e 0,3772, respectivamente. 
Tabela 2. Resultados das Regressões para o período 'Convergência Parcial' ou BRGAAP/IFRS

\begin{tabular}{|c|c|c|c|c|c|c|c|c|}
\hline \multicolumn{9}{|c|}{ Modelo 1* } \\
\hline Variáveis & Coeficientes & Erro Padrão** & Estatística $t$ & $p$-Valor & Estatística F & $p$-Valor & $\mathrm{R}^{2}$ & $\mathrm{R}^{2}$ Ajustado \\
\hline $\mathrm{FCO}_{\mathrm{t}-1}$ & 1,104788 & 0,070071 & 15,76662 & 0,0000 & 788,5408 & 0,0000 & 0,8815 & 0,8803 \\
\hline \multicolumn{9}{|c|}{ Modelo 2* } \\
\hline Variáveis & Coeficientes & Erro Padrão** & Estatística $t$ & $p$-Valor & Estatística F & $p$-Valor & $\mathrm{R}^{2}$ & $\mathrm{R}^{2}$ Ajustado \\
\hline $\mathrm{LL}_{\mathrm{t}-1}$ & 1,798677 & 0,221009 & 8,138491 & 0,0000 & 451,9874 & 0,0000 & 0,8100 & 0,8082 \\
\hline \multicolumn{9}{|c|}{ Modelo 3* } \\
\hline Variáveis & Coeficientes & Erro Padrão** & Estatística $t$ & $p$-Valor & Estatística F & $p$-Valor & $\mathrm{R}^{2}$ & $\mathrm{R}^{2}$ Ajustado \\
\hline $\mathrm{LO}_{\mathrm{t}-1}$ & 0,723413 & 0,384458 & 1,881643 & 0,0426 & 65,82748 & 0,0000 & 0,3831 & 0,3772 \\
\hline \multicolumn{9}{|c|}{ Modelo 4* } \\
\hline Variáveis & Coeficientes & Erro Padrão** & Estatística $t$ & $p$-Valor & Estatística F & $p$-Valor & $\mathrm{R}^{2}$ & $\mathrm{R}^{2}$ Ajustado \\
\hline $\mathrm{FCO}_{\mathrm{t}-1}$ & 1,149087 & 0,038111 & 30,15124 & 0,0000 & 572,3020 & 0,0000 & 0,9159 & 0,9143 \\
\hline $\mathrm{ACCBP}_{\mathrm{t}-1}$ & 0,233512 & 0,033739 & 6,921045 & 0,0000 & & & & \\
\hline \multicolumn{9}{|c|}{ Modelo 5* } \\
\hline Variáveis & Coeficientes & Erro Padrão** & Estatística $t$ & $p$-Valor & Estatística F & $p$-Valor & $\mathrm{R}^{2}$ & $\mathrm{R}^{2}$ Ajustado \\
\hline $\mathrm{FCO}_{\mathrm{t}-1}$ & 1,038275 & 0,057537 & 18,04542 & 0,0000 & 514,8071 & 0,0000 & 0,9074 & 0,9056 \\
\hline $\mathrm{ACCFC}_{\mathrm{t}}$ & $-0,294520$ & 0,050587 & $-5,822105$ & 0,0000 & & & & \\
\hline
\end{tabular}

*Todas as regressões estimadas (Modelo 1 ao Modelo 5) rejeitam a hipótese nula de normalidade dos resíduos. No entanto, considerando o Teorema do Limite Central e considerando o número de observações, o pressuposto da normalidade pode ser relaxado (BROOKS, 2002).

** Erros-padrão estimados aplicando-se a matriz robusta de Newey-West.

Para detectar a presença de multicolinearidade, fez-se uso dos testes FIV (Variance Inflatiom Factor). Obteve-se um FIV de 1,028 para as variáveis $\mathrm{FCO}_{\mathrm{t}-1}$ e $\mathrm{ACCBP}_{\mathrm{t}-1}$, respectivamente, e um FIV de 2,199 para as variáveis $\mathrm{FCO} \mathrm{t}_{\mathrm{t}-1}$ e $\mathrm{ACCFC}_{\mathrm{t}-1}$, respectivamente, concluindo-se pela inexistência de colinearidade (LEVINE; BERENSON; STEPHAN, 2000)

\subsection{Período "Pós convergência" ou "IFRS".}

A Tabela 3 evidencia os resultados das regressões, utilizando cinco medidas contábeis como variáveis independentes e o Fluxo de Caixa Futuro (FCOt) como variável dependente, durante o período "Pós Convergência", considerado, neste estudo, os anos de 2010 e 2011

De acordo com a Tabela 3, todas as regressões estimadas mostraram-se significativas em termos estatísticos ao nível de $1 \%$, uma vez que os p-value obtidos pela estatística $F$ foram inferiores a 0,01 . Quanto à significância das variáveis, todas as variáveis, com exceção da variável ACCBP ,1, mostraram-se significativas estatisticamente ao nível de $1 \%$.

Assim como no período 'Pré Convergência', a regressão com maior poder explicativo foi o Modelo 5 , com um coeficiente de determinação de 0,9124, evidenciando que $91,24 \%$ da variação do Fluxo de Caixa Futuro $\left(\mathrm{FCO}_{t}\right)$ é explicada pelas variáveis Fluxo de Caixa Operacional $\left(\mathrm{FCO}_{t-1}\right)$ em conjunto com os accruals calculados pelo enfoque do Fluxo de Caixa $\left(\right.$ AccFC $\left._{t}\right)$. Da mesma forma dos períodos anteriores ('Pré Convergência e Convergência Parcial), as evidências empíricas suportam que os accruals possuem um conteúdo informacional adicional, conforme Lopes e Martins (2007) salientam.

Ressalta-se que, ao comparar os $\mathrm{R}^{2}$ Ajustados das variáveis explicativas mais relevantes na predição dos Fluxos de Caixa Futuros, dos três períodos em análise, verifica-se aumento considerável do primeiro para o segundo período, porém, há uma leve queda do segundo para o terceiro.

Observa-se, ainda, que o Modelo 3 mostrou-se o segundo mais explicativo, com um coeficiente de determinação de 0,8558 , ou seja, o Lucro Operacional $\left(\mathrm{LL}_{\mathrm{t}-1}\right)$ explica 85,58\% das variações dos Fluxos de Caixa Futuros $\left(\mathrm{FCO}_{\mathrm{t}}\right.$ ). O Modelo 2 mostrou-se o terceiro mais explicativo, com um $\mathrm{R}^{2}$ Ajustado de 0,8376 . Por fim, os Modelos 4 e 1 apresentaram $\mathrm{R}^{2}$ Ajustado de 0,6838 e 0,6768 , respectivamente.

Tabela 3. Resultados das Regressões para o período 'Pós Convergência' ou IFRS

\begin{tabular}{|c|c|c|c|c|c|c|c|c|}
\hline \multicolumn{9}{|c|}{ Modelo 1} \\
\hline Variáveis & Coeficientes & Erro Padrão & Estatística $t$ & $p$-Valor & Estatística F & $p$-Valor & $\mathrm{R}^{2}$ & $\begin{array}{c}\mathrm{R}^{2} \\
\text { Aiustado }\end{array}$ \\
\hline $\mathrm{FCO}_{t-1}$ & 0,706460 & 0,198415 & 3,560515 & 0,0006 & 225,1221 & 0,0000 & 0,6798 & 0,6768 \\
\hline \multicolumn{9}{|c|}{ Modelo 2} \\
\hline Variáveis & Coeficientes & Erro Padrão & Estatística $t$ & $p$-Valor & Estatística F & $p$-Valor & $\mathrm{R}^{2}$ & $\begin{array}{c}\mathrm{R}^{2} \\
\text { Ajustado }\end{array}$ \\
\hline $\mathrm{LL}_{\mathrm{t}-1}$ & 1,398047 & 0,205794 & 6,793442 & 0,0000 & 552,9120 & 0,0000 & 0,8391 & 0,8376 \\
\hline \multicolumn{9}{|c|}{ Modelo 3} \\
\hline Variáveis & Coeficientes & Erro Padrão & Estatística $t$ & $p$-Valor & Estatística F & $p$-Valor & $\mathrm{R}^{2}$ & $\begin{array}{c}\mathrm{R}^{2} \\
\text { Aiustado }\end{array}$ \\
\hline $\mathrm{LO}_{\mathrm{t}-1}$ & 0,902919 & 0,127414 & 7,086489 & 0,0000 & 636,2193 & 0,0000 & 0,8571 & 0,8558 \\
\hline \multicolumn{9}{|c|}{ Modelo 4} \\
\hline Variáveis & Coeficientes & Erro Padrão & Estatística $t$ & $p$-Valor & Estatística F & $p$-Valor & $\mathrm{R}^{2}$ & $\begin{array}{c}\mathrm{R}^{2} \\
\text { Aiustado }\end{array}$ \\
\hline $\mathrm{FC}_{\mathrm{t}-1}$ & 0,717177 & 0,205857 & 3,483859 & 0,0007 & 116,7089 & 0,0000 & 0,6897 & 0,6838 \\
\hline $\mathrm{ACCBP}_{t-1}$ & $-0,083687$ & 0,074453 & $-1,124016$ & 0,2636 & & & & \\
\hline \multicolumn{9}{|c|}{ Modelo 5} \\
\hline Variáveis & Coeficientes & Erro Padrão & Estatística $t$ & $p$-Valor & Estatística F & $p$-Valor & $\mathrm{R}^{2}$ & $\begin{array}{c}\mathrm{R}^{2} \\
\text { Aiustado }\end{array}$ \\
\hline $\mathrm{FCO}_{\mathrm{t}-1}$ & 0,958879 & 0,091830 & 10,44186 & 0,0000 & 558,5619 & 0,0000 & 0,9140 & 0,9124 \\
\hline $\mathrm{ACCFC}_{t-1}$ & 0,669129 & 0,078811 & 8,490325 & 0,0000 & & & & \\
\hline
\end{tabular}


*Todas as regressões estimadas (Modelo 1 ao Modelo 5) rejeitam a hipótese nula de normalidade dos resíduos. No entanto, considerando o Teorema do Limite Central e considerando o número de observações, o pressuposto da normalidade pode ser relaxado (BROOKS, 2002).

** Erros-padrào estimados aplicando-se a matriz robusta de NeweyWest.

Para detectar a presença de multicolinearidade, fez-se uso dos testes FIV (Variance Inflatiom Factor). Obteve-se um FIV de 4,710 para as variáveis $\mathrm{FCO}_{t-1}$ e ACCBP ${ }_{t-1}$, respectivamente, e um FIV de 2,724 para as variáveis FCO e ACCFC, respectivamente, concluindose pela inexistência de colinearidade (LEVINE; BERENSON; STEPHAN, 2000).

Por fim, observou-se um aumento da capacidade explicativa do lucro líquido e do fluxo de caixa operacional combinado com os accruals, calculados pelo enfoque do fluxo de caixa, durante o período pós convergência, comparativamente aos períodos pré e convergência parcial. Adicionalmente, os resultados evidenciam que os lucros desagregados em fluxo de caixa e accruals aumentam significativamente a capacidade preditiva dos fluxos de caixa futuros

Dessa forma, pode-se concluir que os accruals possuem um poder informativo adicional em predizer os fluxos de caixa futuros, corroborando os achados de Barth, Cram e Nelson (2001) e Malacrida (2009).

\section{CONSIDERAÇÕES FINAIS}

Este trabalho investigou a relação entre as variáveis lucro (líquido e operacional), fluxo de caixa e accruals (pelo enfoque do Balanço Patrimonial e Fluxo de Caixa) na explicação dos valores dos fluxos de caixas futuros. Além disso, o trabalho buscou verificar se houve uma melhor explicação dos fluxos de caixa futuros, em virtude do processo de convergência das normas contábeis brasileiras às internacionais.

Observou-se um aumento da capacidade explicativa do lucro líquido e do fluxo de caixa operacional combinado com os accruals, calculados pelo enfoque do fluxo de caixa, durante o período pós convergência, comparativamente aos períodos pré e convergência parcial. Adicionalmente, os resultados indicaram, nos três períodos analisados, que o fluxo de caixa operacional e os accruals, de forma conjunta, possuem maior poder de explicação dos fluxos de caixa futuros em relação às outras variáveis analisadas. Como era de se esperar, os accruals possuem um poder informacional adicional, uma relevância maior, em explicar os fluxos de caixa futuros, o que está de acordo com os princípios direcionadores da Teoria da Contabilidade, assim como os trabalhos de Barth, Cram e Nelson (2001) e Malacrida (2009).

Outro ponto adicional pode ser destacado: dos três períodos analisados, dois evidenciaram que os accruals calculados pelo enfoque do Fluxo de Caixa conseguem explicar melhor os Fluxos de Caixa Futuros. Tais resultados estão em consonância com os achados de Collins e Hribar (2000), onde mostraram que os accruals mensurados pelo enfoque da Demonstração do Fluxo de Caixa estão menos susceptíveis a erros em sua mensuração do que aqueles calculados pelo enfoque do Balanço Patrimonial.
Portanto, os resultados da pesquisa evidenciam que as variáveis fluxo de caixa operacional combinada com accruals são mais relevantes, em comparação as outras analisadas, na predição dos Fluxos de Caixa Futuros, pois conseguem explicar de maneira mais eficaz, durante os três períodos de análise, a variação dos Fluxos de Caixa Futuros.

\section{REFERÊNCIAS}

ARNOLD, A.J., et. al. The relationship between earnings, funds flows and cash flows: evidence for the UK. Accounting and Business Research, v. 22, n. 85, p. 13-19, 1991.

BARTH, M. E, et. al. Accruals, cash flows and equity values. Review of Accounting Studies, v.3, p. 205229, 1999.

BARTH, M. E.; CRAM, D.P.; NELSON, K. K. Accruals and the prediction of future cash flows. The Accounting Review, v. 76, n.1, p. 27-58, 2001.

BARTH, M. E.; LANDSMAN, W. R.; LANG, M. H. International accounting standards and accounting quality. Journal of Accounting Research, v.46, p.467-498, 2008.

BARTOV, E.; GOLDBERG, S.R.; KIM, M. The valuation-relevance of earnings and cash flows: an international perspective. Journal of International Financial Management and Accounting, v.12, n.12, p. 103-132, 2001.

BOWEN, R.M.; BURGSTAHLER, D.; DALEY L.A., Evidence on the relationships. between earnings and various measures of cash flow. The Accounting Review, v.61, n.4, p. 713-725, 1986.

BRASIL. Lei n ${ }^{\circ} 11.638$, de 28 de dezembro de 2007.

BROOKS, C. Introductory econometrics for finance. Cambridge: Cambridge University Press, 2002.

CALIXTO, L. Análise das pesquisas com foco nos impactos da adoção do IFRS em países europeus. Revista Contabilidade Vista \& Revista, v. 21, n.1, p. 157-187, 2010.

COLLINS, D.W.; HRIBAR, P. Earnings-based and accrual-based market anomalies: one effect or two? Journal of Accounting and Economics, v.29, n.1, p. 101-123, 2000.

CPC. Comitê de Pronunciamentos Contábeis. Pronunciamento conceitual básico. Estrutura conceitual para a elaboração e apresentação das demonstrações contábeis. Brasília, 2008.

CPC. Comitê de Pronunciamentos Contábeis. Pronunciamento Técnico CPC 03- Demonstração do Fluxo de Caixa. Brasília, 2008.

CPC. Comitê de Pronunciamentos Contábeis. Pronunciamentos Técnicos Contábeis 2008. Brasília, 2008.

DECHOW, P. M. Accounting earnings and cash flows as measures of firm performance: the role of accounting accruals. Journal of Accounting and Economics, v. 18, n. 1-2, p. 3-42, 1994. 
DECHOW, P. M; DICHEV, I.D. The quality of accruals and earnings: the role of accruals estimation error. The Accounting Review. v.77, p. 35-59, 2002.

DECHOW, P.M.; KOTHARI, S.P.; WATTS, R.L. The relation between earnings and cash flows. Journal of Accounting and Economics, v.25, n.2, p. 133168, 1998.

DECHOW, P.M.; SLOAN, R.G.; SWEENEY, A.P. Detecting Earnings Management. The Accounting Review, v.70, n.2, p. 193-225, 1995.

EDWARDS, E. O.; BELL, P. W. The Theory and measurement of business income. Los Angeles: University of California, 1964.

FASB. Financial Accounting Standards Board. Statement of Financial Accounting Concepts $\mathrm{n}^{\circ} 1$. Objectives of financial reporting by business enterprises. Stamford, 1978.

FINGER, C. The ability of Earnings to predict Future Earnings and Cash Flow. Journal of Accounting Research, v.32, p.210-223, 1994.

GREENBERG, R.; JOHNSON, G.; RAMESH, K. Earnings versus cash flow as a predicator of future cash flow measures. Journal of Accounting, Auditing and Finance, v. 14, n. 11, p.266-277, 1986.

HENDRIKSEN, E. S.; VAN BREDA M. F. Teoria da contabilidade. São Paulo: Atlas, 2007.

HUNG, M.; SUBRAMANYAM, K. R. Financial statement effects of adopting international accounting standards: the case of Germany. Review of Accounting Studies, v.12, p. 623-657, 2007.

IASB. International Accounting Standards Board. International Accounting Standard $\mathrm{n}^{\circ} 1$. Presentation of financial statements. 2008.

IUDÍCIBUS. S. Teoria da Contabilidade. 10. Ed. São Paulo: Atlas, 2010.

LAFOND, R. Is the accrual anomaly a global anomaly? SSRN eLibrary SSRN, 2005. Disponível em < http://ssrn.com/paper=782726>. Acesso em 01 out 2011.

LEV, B.; LI, S.; SOUGIANNIS, T. Accounting estimates: pervasive, yet of questionable usefulness. Working Paper, New York University, New York, 2005.

LEVINE, D. M.; BERENSON, M. L.; STEPHAN, D. Estatística: teoria e aplicações. Rio de Janeiro: LTC, 2000.

LIMA, J. B. N. A relevância da informação contábil e $o$ processo de convergência para as normas ifrs no brasil. 2010. Tese (Doutorado em Ciências Contábeis) - Programa de Pós-Graduação em Controladoria e Contabilidade - FEA/USP, São Paulo, 2010.

LOPES, A.B.; MARTINS, E. Teoria da contabilidade: uma nova abordagem. São Paulo: Atlas, 2007.

LUSTOSA, P; SANTOS, A. O poder relativo do lucro contábil e do fluxo de caixa das operações para prever fluxos de caixa futuros: um estudo Empírico no Brasil. REPEC, v.1, n.1, 2007.

MALACRIDA, M. J. C. A relevância do lucro líquido versus fluxo de caixa operacional para o mercado de ações brasileiro. 2009. Tese (Doutorado em Ciências Contábeis) - Programa de Pós-Graduação em Controladoria e Contabilidade - FEA/USP, São Paulo, 2009.

MARTINEZ, A.L. Gerenciamento dos resultados contábeis: estudo empírico das companhias abertas brasileiras. 2001. Tese. (Doutorado em Ciências Contábeis) - Programa de Pós-Graduação em Controladoria e Contabilidade - FEA/USP, São Paulo, 2001.

MARTINS, E. Contabilidade versus fluxo de caixa. Caderno de Estudos FIPECAFI, v.2, p. 1-15, 1990.

MARTINS, G. A. Manual para elaboração de monografias e dissertações. 3. Ed. São Paulo: Atlas, 2002.

MORAIS, A. I.; CURTO, J. D. Accounting quality and the adoption of IASB Standards - Portuguese Evidence. Revista Contabilidade \& Finanças, v.19, n. 48, p. 103-111, 2007.

NISKANEN, J.; KINNUNEN, J.; KASANEN, E. A note on the information content of parent company versus consolidated earnings in Finland. European Accounting Review, v. 7, p. 31-40, 1998.

NIYAMA, J. K. Contabilidade internacional. São Paulo: Atlas, 2010.

RICHARDSON, S. A., et al. Accrual reliability, earnings persistence and stock prices. Journal of Accounting and Economics, v.39, n.2, p.437-485, 2005. ROSS, S. A.; WESTERFIELD, R. W.; JAFFE, J. F. Corporate finance. New York: McGraw-Hill, 2001.

PERCY, M.; STOKES, D.J. Further evidence on empirical relationships between earnings and cash flows. Accounting and Finance, v. 32, n.23, p. $27-$ 49, 1992.

SLOAN, R.G. Do stock prices fully reflect information in accruals and cash flows about future earnings? Accounting Review, v.71, n.3, p. 289-315, 1996.

YAMAMOTO, M.M.; SALOTTI, B.M. Informação contábil: Estudos sobre a sua Divulgação no Mercado de Capitais. São Paulo: Atlas, 2006. 